\title{
A REALIDADE SOCIOESPACIAL DOS ESPAÇOS PÚBLICOS DE LAZER DE TERESINA-PI: UTILIZAÇÃO E CONSERVAÇÃO.
}

\author{
Laudenides Pontes dos Santos ${ }^{1}$ \\ Silvia Aparecida Guarnieri Ortigoza ${ }^{2}$
}

\section{Resumo}

Este artigo visa analisar como o lazer tem sido vivenciado na cidade de Teresina-PI, apurando o estado de conservação dos espaços públicos dedicados ao lazer e as formas como são utilizados pelos sujeitos. Como objetivos específicos lista-se: identificar quais os tipos de espaços mais utilizados; Verificar a frequência de uso destes espaços; Caracterizar a programação de atividades e conservação. Como procedimento metodológico adotou-se a pesquisa bibliográfica, a pesquisa documental e a pesquisa de campo por meio de entrevistas junto aos órgãos de planejamento da cidade. De forma complementar foram feitas visitas aos espaços selecionados, e aplicados questionários junto aos moradores de dez bairros da cidade de Teresina/PI. Como resultados verificou-se que muitos moradores até utilizam os espaços públicos de lazer da aludida cidade, no entanto, ainda existem expressivos entraves que dificultam a ampliação do uso devido, como por exemplo, a precária conservação e manutenção dos espaços e a inexistência de segurança nos locais. Para além desses, identificou ainda a inexistência de uma programação de atividades de lazer e recreativas, que possibilitasse a motivação pelo uso e participação.

Palavras-chaves: Espaços públicos, lazer, Teresina-PI.

\section{THE SOCIOESPACIAL REALITY OF THE PUBLIC LEISURE SPACES OF TERESINA-PI: USE AND CONSERVATION.}

\begin{abstract}
This article aims to analyze how leisure has been experienced in the city of Teresina-PI, investigating the state of preservation of the public spaces dedicated to local leisure and the ways that such spaces are used by the subjects. As specific objectives, are listed: identify which types of spaces are most used; Check how often these spaces are used; Characterize the schedule of activities and conservation. As a methodological procedure were adopted bibliographic research, documentary research and field research through interviews with the planning sectors of the city. In a complementary way, the selected spaces were visited, and questionnaires were applied to ten residents of the city of Teresina / PI. As results it was verified that many residents even use the public leisure spaces of the mentioned city, however, there are still significant obstacles that make the increase of the proper use of such

\footnotetext{
${ }^{1}$ Doutora em Geografia pelo Programa de Pós-graduação em Geografia do Instituto de Geociências e Ciências Exatas, da Universidade Estadual Paulista "Júlio de Mesquita Filho" - UNESP/ Campus Rio Claro. Professora do Instituto Federal de Educação, Ciência e Tecnologia do Piauí, campus Teresina-Central. E-mail: laudenides.pontes@ifpi.edu.br.

${ }^{2}$ Professora livre docente do Departamento de Geografia e docente permanente do Programa de Pós-graduação em Geografia do Instituto de Geociências e Ciências Exatas da Universidade Estadual Paulista "Júlio de Mesquita Filho" - UNESP/ Campus Rio Claro. E-mail: sago@ rc.unesp.br.
}

Sociedade e Território - Natal. Vol. 29, N. 2, p. 154-174, Jul./Dez. de 2017. 
spaces difficult, such as the precarious conservation and maintenance of such spaces and the lack of security in these places. In addition to these, it was also identified the lack of a schedule of leisure and recreational activities, which motivated the use and participation in such spaces.

Keywords: Public spaces, leisure, Teresina-PI.

\section{LA REALIDAD SOCIOESPACIAL DE LOS ESPACIOS PUBLICOS DE RECREACIÓN DE TERESINA-PI: UTILIZACIÓN Y CONSERVACIÓN.}

\section{Resumen}

Este artículo visa hacer un analisis de como la recreación tiene sido vivenciada en la ciudad de Teresina-PI, cotejando el estado de conservación de los espacios públicos dedicados a la recreación y a las formas como son utilizados por los sujetos. Como objetivos específicos se lista: identificar cuales los tipos de espacios más utilizados; verificar la frecuencia del uso de estos espacios; caracterizar la programación de actividades y conservación. Como procedimentos metodológicos se adoptó la investigación bibliográfica, la investigación documental y la investigación de campo por medio de encuestas junto a los órganos de planificación de la ciudad. De forma complementar fueron hechas visitaciones a los espacios elegidos, y aplicados cuestionários junto a los residentes de diez barrios de la ciudad de Teresina/PI. Como resultados se verificó que muchos residentes hasta utilizan los espacios públicos de recreación de la ciudad. Sin embargo, todavia existen expresivos obstáculos que dificultan la ampliación de uso debido, como por exejemplo, la precária conservación y manuntención de los espacios y la inexistencia de seguridad en los locales. Además de eso, se identificó aún la inexistencia de una programación de actividades de recreación, que permitiese la motivación por el uso y participación.

Palabras - llave: Espacios públicos, recreación, Teresina-PI.

\section{INTRODUÇÃO}

Com o objetivo de contribuir para os estudos relacionais entre espaço público e o lazer nas cidades no Brasil, considerando o crescimento da importância do lazer na sociedade atual e as mudanças por quais vem passando o espaço público, este artigo discute a situação dos espaços públicos de lazer da cidade de Teresina-PI, no que diz respeito á conservação e utilização.

Atualmente as cidades crescem rapidamente, a prioridade é o valor econômico do espaço e não o seu valor de uso para os citadinos, por causa da mercantilização do espaço. Dotar estas cidades de equipamentos estruturais não vem sendo uma tarefa fácil, principalmente na questão do lazer. Neste contexto, torna-se importante estudar como as cidades são dotadas de equipamentos de lazer, procurando avaliar a dinâmica espacial envolvida. Esta pesquisa vai neste sentido, à procura de analisar o lazer como um importante Sociedade e Território - Natal. Vol. 29, N. 2, p. 154-174, Jul./Dez. de 2017. 
componente para a qualidade de vida das pessoas, e trazer uma leitura crítica das cidades, como um lugar de moradia e de trabalho, mas que necessita de oferecer possibilidades de lazer aos seus moradores.

Com relação à metodologia da pesquisa, trata-se de um estudo de caso, uma vez que estudou a organização dos espaços de lazer urbano na cidade de Teresina-PI, a partir da análise dessa realidade em alguns bairros da aludida cidade. Assim, o estudo está configurado como de casos múltiplos (GIL, 2010), pois foram analisados conjuntamente mais de um caso para investigar o fenômeno em questão.

Os procedimentos metodológicos adotados foram: pesquisa bibliográfica e pesquisa documental que teve como principal fonte o documento Teresina em Bairros 2013 a fim de identificar os espaços de lazer dos bairros selecionados, visitas e observação, além disso, foi realizada uma entrevista com secretário de lazer e a aplicação de questionários junto aos moradores dos bairros pesquisados.

Informa-se que foram aplicados 150 questionários dotados de perguntas abertas e fechadas com foco nos moradores de cada zona pesquisada, totalizando um quantitativo de 750 questionários. Estes foram aplicados onde havia grande fluxo de pessoas. Os indivíduos foram escolhidos aleatoriamente observando apenas a diversificação dos sujeitos quanto a faixa etária e sexo. As pessoas foram abordadas e questionadas se gostariam de colaborar com a pesquisa.

O campo de investigação foi à cidade de Teresina-PI, a amostra utilizada abrangeu dez de seus bairros, sendo dois de cada zona da cidade, a saber: Mafuá e Piçarra (Centro), São João e Vale Quem Tem (Leste), Mocambinho e São Joaquim (Norte), Itararé e Renascença (Sudeste), Parque Piauí e Saci (Sul), conforme Mapa 1. 
Figura 01: Localização dos bairros estudados

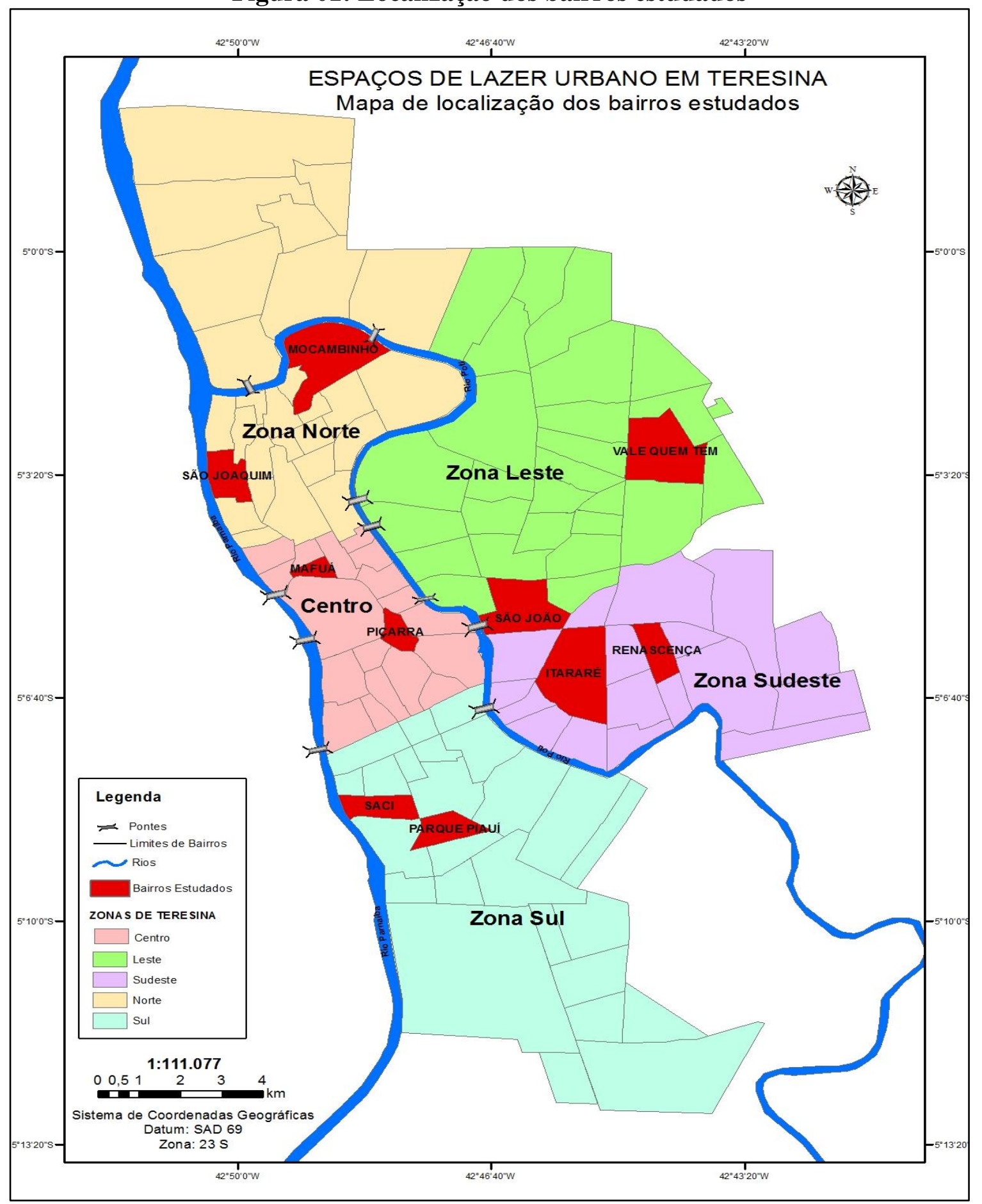

Fonte: Elaborado por Silvana Sousa (2014).

\section{O LAZER E OS ESPAÇOS PÚBLICOS NA CIDADE}

Nas últimas décadas, o tema lazer tem ganhado mais espaço, tanto nas discussões acadêmicas quanto na própria mídia. Gomes e Melo (2003) apontam os seguintes motivos para essa maior valorização: a ligação entre cultura e lazer, a massificação e comercialização Sociedade e Território - Natal. Vol. 29, N. 2, p. 154-174, Jul./Dez. de 2017. 
de produtos culturais, a crescente indústria do lazer que se tornou um negócio promissor na atualidade, o aumento de iniciativas governamentais ligadas ao lazer, e ainda, o questionamento do papel do trabalho na sociedade.

Para Dumazedier (2008), duas condições prévias foram necessárias para que o lazer se tornasse possível para a maioria dos trabalhadores: primeira, a desvinculação das obrigações sociais dos rituais; a segunda faz menção ao trabalho profissional ter ganhado mais destaque do que outras atividades, a partir da definição entre a hora do trabalho e o tempo livre. Dessa forma, para o autor só é possível falar de lazer para as sociedades industriais, visto que nos outros tipos de organização esta separação não era muito nítida.

Foi, portanto, após a Primeira Revolução Industrial que as discussões acerca do lazer ganharam força, pois os benefícios da produção em massa não atingiram todas as classes. De um lado, a classe dominante podia usufruir dos bens produzidos; do outro, a classe operária sofria com a exploração, haja vista que tinha pouco tempo para descanso e lazer devido às massacrantes jornadas de trabalho. Foi neste período que o lazer passou a ser tratado como esfera importante da vida social:

O lazer como instância distinta e específica da vida social só é percebido com o advento da Revolução Industrial e a separação dos espaços familiares, comunitários e profissionais, ou seja, existe no objeto lazer um aspecto histórico de "nãotrabalho" (GUTIERREZ, 2001, p. 6).

Como um produto da sociedade industrial, pode-se dizer, então, que o tempo para o lazer surgiu, de um lado, pelas lutas e movimentos sociais por aumento do tempo livre; e por outro, da própria necessidade das indústrias em vender seus produtos, uma vez que era necessário que o trabalhador tivesse disponibilidade para consumir. Além disso, a diminuição dos controles institucionais da família, das autoridades religiosas e políticas permitiu maior liberdade ao indivíduo de como dispor deste novo tempo: "Uma nova necessidade social do indivíduo a dispor para si mesmo, a gozar de um tempo, cujas atividades antigamente eram em parte impostas pela empresa, pelas instituições sócio-espirituais, sociopolíticas ou familiais" (DUMAZEDIER, 2008, p. 20).

Logo, consideramos o lazer como um produto da sociedade industrial que separou, em lados opostos, o tempo para o trabalho e o tempo livre. Foi com a institucionalização deste tempo que surgiu a necessidade de se pensar em atividades para preenchê-lo, tanto que a busca pelo lazer figura como uma das primeiras opções. O lazer surge como um fenômeno urbano, pois derivou da industrialização que ocorreu nas cidades, mas atualmente com as 
novas formas de organização social, cultural e com o poder da informação também chega ao espaço rural.

Não obstante ao grande leque de atividades que podem ser consideradas lazer, este não é vivido igualmente pela população. Em linhas gerais, pode-se dizer que o acesso ao lazer pode ser restrito devido a fatores como, a condição socioeconômica, faixa etária, grau de instrução, o sexo e o tempo.

\begin{abstract}
Dessa forma, a classe social, o nível de instrução, a faixa etária, o sexo, o acesso ao espaço, a questão da violência crescente nos centros urbanos, entre outros fatores, limita o lazer a uma minoria da população, principalmente se considerarmos a frequência na prática e a sua qualidade (MARCELLINO, 2006, p. 16).
\end{abstract}

A sociedade capitalista é marcada por contradições e desequilíbrios sociais e econômicos. As desigualdades de acesso aos meios de produção são refletidas no acesso aos serviços de educação, saúde, transporte e também de lazer. Acrescenta-se aí, sobremaneira, o acesso ao lazer, uma vez que este é cada vez mais transformado em mercadoria, restringindo o seu acesso conforme o poder aquisitivo das pessoas.

Apesar de ter se tornado uma necessidade social com o advento dos horários rígidos do trabalho e a separação deste com o lúdico, o tempo para lazer é reduzido para muitas pessoas devido as grandes jornadas de trabalho. No que se refere à liberdade individual de escolha sobre a atividade de lazer, o leque de opções é muito reduzido, por conta de fatores estruturais, como a falta de recursos e de insuficiência de espaços públicos onde estas atividades possam ser praticadas. Até mesmo a casa, unidade primeira de realização deste lazer, para muitos, é apenas um sonho; para outros, é um espaço pequeno, apenas o necessário para a sobrevivência diária.

É evidente que o lazer não possui a miraculosa propriedade de anular os condicionantes sociais, nem de instaurar o reinado da liberdade absoluta, mas a liberdade de escolha dentro do tempo de lazer é uma realidade mesmo que limitada e em parte ilusória (DUMAZEDIER, 2008, p. 58).

Embora seja na escolha do lazer que o indivíduo tem mais liberdade que no trabalho, é ilusório pensar que esta liberdade é total, uma vez que a condição social e espacial restringe sobremodo suas possibilidades de lazer.

A sociedade atual encontra-se ainda longe da meta da liberdade e dos direitos sociais para todos. Dificilmente, alguém pode dizer-se totalmente livre para a escolha do tipo de lazer, porque, na prática as possibilidades temporais e espaciais reais limitam, muitas vezes, as preferências individuais (LIMA, 2006, p. 82-83). 
Um dos condicionantes para a prática do lazer é o espaço, para este artigo o viés analisado é o espaço público. Considera-se para esta pesquisa, como espaços de lazer urbano, espaços públicos que podem de alguma forma, propiciar momentos de lazer à população, de forma gratuita ou a preços pequenos, como: praças, parques ambientais, áreas verdes, quadras de esportes, academias públicas de ginástica, parquinhos para crianças, ginásios poliesportivos, teatros, museus, centros culturais, cinemas e centros sociais. Conforme Azevedo (2013): "Sob o ponto de vista material, o espaço público de lazer pode ser entendido como uma área geralmente mantida pelo Poder Público, cuja infraestrutura e elementos paisagísticos favoreçam a prática de atividades de lazer e recreação” (AZEVEDO, 2013, p. 64).

Esses espaços, além de proporcionarem melhor qualidade de vida aos citadinos, podem contribuir, segundo Marcellino (2001), para o processo de valorização e conservação do patrimônio histórico, cultural, ambiental, social, formal, técnico ou afetivo, de modo a propiciar uma vivência mais rica e prazerosa na cidade em que se vive, estabelecendo pontos de referência e vínculos afetivos, além de preservar as identidades locais e aumentar o potencial turístico.

Utiliza-se o conceito de lazer elaborado por Dumazedier (2008), que considera como lazer as atividades que o indivíduo pode fazer livremente, seja para repousar, sejam para divertir-se, recrear-se e entreter-se; ou ainda, para desenvolver sua formação ou informação de maneira desinteressada, sua participação social voluntária ou sua livre capacidade criadora, após livrar-se ou desembaraçar-se das obrigações profissionais, familiares e sociais.

Os espaços ou equipamentos de lazer públicos na cidade são necessários para o bemestar dos citadinos, sejam por proporcionar lugares para atividades físicas, brincadeiras, jogos, eventos culturais, ou ainda por representar um espaço que aproxima os sujeitos da natureza, tendo em vista a grande artificialização da paisagem que ocorre principalmente nas grandes cidades. $\mathrm{O}$ contato com a natureza pode ser feito durante passeios em praças e parques.

Os espaços públicos abertos são, a cada dia, mais necessários e de vital importância
nos meios urbanos. Esses espaços podem agregar qualidade ao ambiente urbano,
através do favorecimento de condições técnicas ligadas ao uso (funcionalidade),
condições ambientais e sanitárias (salubridade) e condições de convívio e lazer
(sociabilidade), além de fornecer atributos estéticos ao lugar (CUNHA, 2003, p. 31).

Além desse contato com a natureza, estes espaços podem propiciar o convívio social que hoje é tão prejudicado pelo isolamento das pessoas nas cidades. Sem o convívio não há 
uma formação de identidade e pertencimento a uma comunidade, dessa forma, as ações reivindicatórias são enfraquecidas:

Com o crescimento desordenado das cidades, agrava-se o isolamento de seus habitantes, e sua condição de passividade frente às decisões que afetam diariamente a sua vida diária. É perfeitamente lógica, nesse esquema de raciocínio, a falta de espaço para o lazer, quase sempre colocado numa falsa hierarquia de necessidades. Nas grandes cidades atuais sobra pouca ou quase nenhuma oportunidade espacial para a convivência (MARCELLINO; BARBOSA; MARIANO, 2008, p. 138).

A falta de espaços públicos adequados dificulta o lazer. A infraestrutura espacial não acompanha o crescimento demográfico urbano. Para tornar o lazer mais acessível, primeiramente, é preciso pensar que todos os cidadãos têm o direito à cidade, e, dessa forma, os espaços de lazer devem ser concebidos de forma mais democrática possível.

O urbano que é criado à luz do sistema capitalista é resultado de interesses econômicos e reflete a própria sociedade, ou seja, possui diferenciações ou segregações.

Da diferenciação da localização das classes sociais no espaço urbano e na fragmentação da cidade, evidencia-se a segregação espacial da cidade capitalista, verificada basicamente devido ao diferencial que cada grupo social tem de pagar pelo lugar que ocupa, o qual apresenta, além de características construtivas diferentes, também características distintas do seu entorno (LIMA, 2006, p. 46).

Outra questão a ser ponderada no tocante ao lazer nos espaços urbanos é a violência. Os espaços de lazer, muitas vezes, não são utilizados para o fim a que foram destinados por causa do medo da população, uma vez que os índices de violência nas cidades estão cada vez mais expressivos. Na cidade de Teresina-PI, foi possível verificar este fato. Muitos moradores afirmam não frequentar praças, parques, quadras esportivas por causa da insegurança desses locais. Dessa forma, estes espaços vão se tornando vias de passagem como afirma Marcellino: "com relação às ruas, e mesmo que se considerem as praças, quase sempre são concebidas como locais de acesso, de passagem, de locomoção. Transitá-las é uma aventura” (2006, p. $30)$.

A violência marginaliza os espaços públicos, inclusive os de lazer. As pessoas, por sua vez, buscam alternativas, seja sua própria casa, seja através de equipamentos privados. O lazer apresenta um mercado rentável que cria espaços para que as pessoas possam usufruir desses momentos, principalmente nas grandes cidades onde o espaço cada vez mais é escasso e se torna um produto valorizado. O espaço urbano é mercadoria, utilizado em empreendimentos lucrativos ou até mesmo para especulação imobiliária. 
É preciso destacar também que a ineficiência do poder público em oferecer lazer aos citadinos não diz respeito apenas à falta de espaços, mas envolve outras questões como a conservação, a programação de eventos destes espaços, a segurança. Uma política pública para o lazer envolve muitas questões como já afirmava Dumazedier: "para tanto se impõem uma política ousada de reforma da legislação, dos equipamentos e dos homens” (2008, p. 167).

\section{UTILIZAÇÃO E CONSERVAÇÃO DOS ESPAÇOS PÚBLICOS DE LAZER NA CIDADE DE TERSINA-PI}

A prática do lazer envolve um conjunto de fatores como, por exemplo: tempo, atitude, espaço disponível, a escolha individual em praticar ou não alguma atividade que existe, mesmo que limitada por modismos ou por impedimentos de ordem econômica, política e cultural. É no lazer que o sujeito tem maior liberdade. Desse modo, para entender a dinâmica dos espaços públicos de lazer na cidade de Teresina-PI, verificamos com que frequência à população utiliza esses espaços disponíveis. Sobre esta questão, obtivemos os seguintes resultados dispostos na Tabela 1.

Tabela 1 - Frequência dos moradores nos espaços públicos de lazer do seu bairro

\begin{tabular}{l||c||c|c}
\hline \hline \multicolumn{1}{c||}{ ZONA/BAIRRO } & NÃO & SIM & TOTAL \\
\hline \hline Centro/ Mafuá & 38 & 37 & 75 \\
& $51 \%$ & $49 \%$ & $100 \%$ \\
\hline \hline Centro/ Piçarra & 52 & 23 & 75 \\
& $69 \%$ & $31 \%$ & $100 \%$ \\
\hline \hline Leste/ São João & 40 & 35 & 75 \\
& $53 \%$ & $47 \%$ & $100 \%$ \\
\hline \hline Leste/ Vale Quem Tem & 27 & 48 & 75 \\
& $36 \%$ & $64 \%$ & $100 \%$ \\
\hline \hline Norte/ Mocambinho & 23 & 52 & 75 \\
& $31 \%$ & $69 \%$ & $100 \%$ \\
\hline \hline Norte/ São Joaquim & 24 & 51 & 75 \\
& $32 \%$ & $68 \%$ & $100 \%$ \\
\hline \hline Sudeste/ Itararé & 21 & 54 & 75 \\
& $28 \%$ & $72 \%$ & $100 \%$ \\
\hline Sudeste/ Renascença & 34 & 41 & 75 \\
& $45 \%$ & $55 \%$ & $700 \%$ \\
\hline \hline Sul/ Parque Piauí & 42 & 33 & $100 \%$ \\
\hline \hline Sul/Saci & $56 \%$ & $44 \%$ & 75 \\
& 23 & 52 & $100 \%$ \\
\hline \hline Total & $31 \%$ & $69 \%$ & $\mathbf{7 5 0}$ \\
& $\mathbf{3 2 4}$ & $\mathbf{4 2 6}$ & $\mathbf{1 0 0 \%}$ \\
\hline \hline
\end{tabular}

Fonte: Pesquisa de Campo (ago. 2012).

Sociedade e Território - Natal. Vol. 29, N. 2, p. 154-174, Jul./Dez. de 2017. 
A maioria dos sujeitos da pesquisa, ou seja, 57\% frequentam as áreas de lazer do bairro onde moram, na análise geral. Os bairros nos quais se verificaram a maior frequência foram: Itararé (72\%), Saci e Mocambinho (69\%) e São Joaquim (68\%). Em quatro bairros, menos da metade da população afirma utilizar os equipamentos de lazer do seu bairro: Mafuá, Piçarra, São João e Parque Piauí.

A maior presença de equipamentos nos bairros pode ser uma das variáveis que contribui para um maior percentual de utilização. No caso dos bairros Mafuá e Piçarra, a baixa utilização pode ser explicada pela existência de poucos espaços no bairro. Entretanto, dois casos chamam a atenção São João e Parque Piauí possuem equipamentos, porém, estes não são muito utilizado, daí vem a importância de se analisar outras variáveis na utilização dos espaços públicos de lazer.

No primeiro caso, pode acontecer de a população ter acesso a outros tipos de lazer, por sua faixa de renda ser maior: "as classes sociais média e alta atribuem à cidade a função exclusiva de circulação, já que podem desfrutar de lazer em seus espaços privatizados. Porém, para as classes mais pobres, a cidade continua com a função de lazer, de morar, de trabalho e de circulação" (MARCELLINO, et al., 2008, p. 141). No segundo caso, podemos citar o abandono em que se encontram os espaços de lazer do bairro; um exemplo é o Centro Social Urbano (CSU) muito citado por seus moradores, mas que se encontra deteriorado (Figura 02) e sem condições para as práticas de lazer. Atualmente o local abriga oficinas, aulas de Capoeira e encontros da terceira idade, enquanto as atividades esportivas deixaram de ser realizadas e o local se tornou alvo de usuários de drogas - até assassinatos já ocorreram no local.

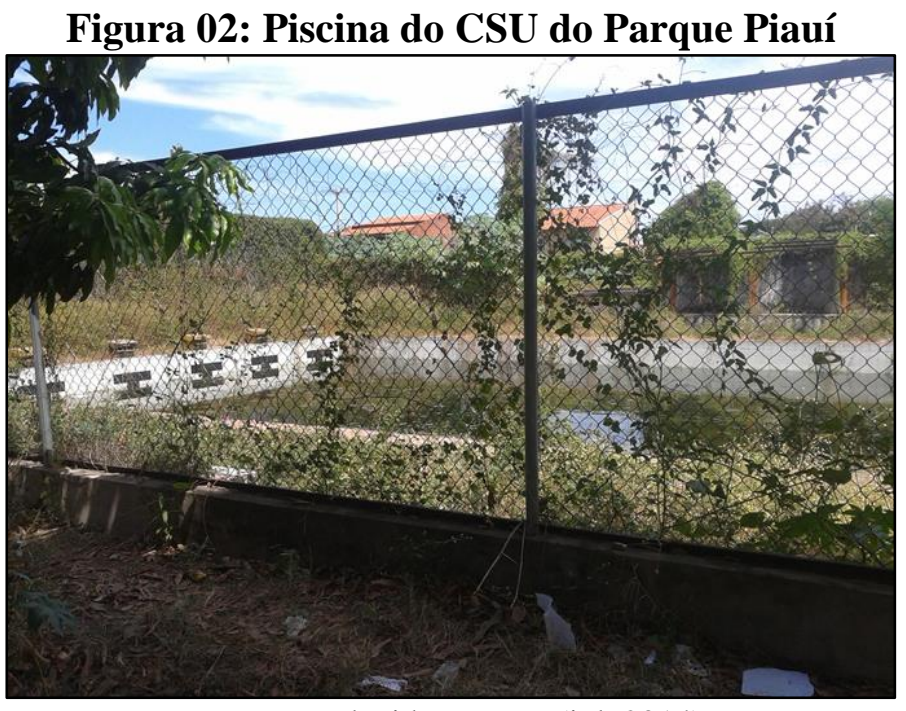

Fonte: Laudenides Pontes (jul. 2014).

Sociedade e Território - Natal. Vol. 29, N. 2, p. 154-174, Jul./Dez. de 2017. 
Convém assinalar que, muitas vezes, a rotina de trabalho impede as pessoas de perceber o lazer como um componente importante em suas vidas para a busca da realização e felicidade. Aliado a isso está o forte apelo do sistema capitalista para que cada um de nós seja mais produtivo, voltado ao trabalho e à acumulação de bens. Apesar disso, é inegável a contribuição do lazer para a qualidade de vida dos indivíduos, daí vem a importância da existência de espaços públicos para este fim:

Dentre os valores funcionais, a principal atribuição dos espaços livres é a opção de lazer e recreação que essas áreas oferecem, principalmente em bairros populares onde os espaços públicos tornam-se bastante utilizados devido à impossibilidade de usufruir o lazer pago, presente nos clubes privados, cinemas, parques de diversão, shopping centers e outros (ROBBA E MACEDO, 2010 apud AZEVEDO, 2013, p. 66).

Sobre a utilização, conclui-se que, apesar de existirem bairros com frequência menor, a população, em sua maioria, utiliza de alguma forma os espaços existentes em seu bairro, como pode ser visualizado no Gráfico 01, a seguir.

\section{Gráfico 01 - Frequência dos moradores pesquisados nas áreas de lazer do bairro onde} moram

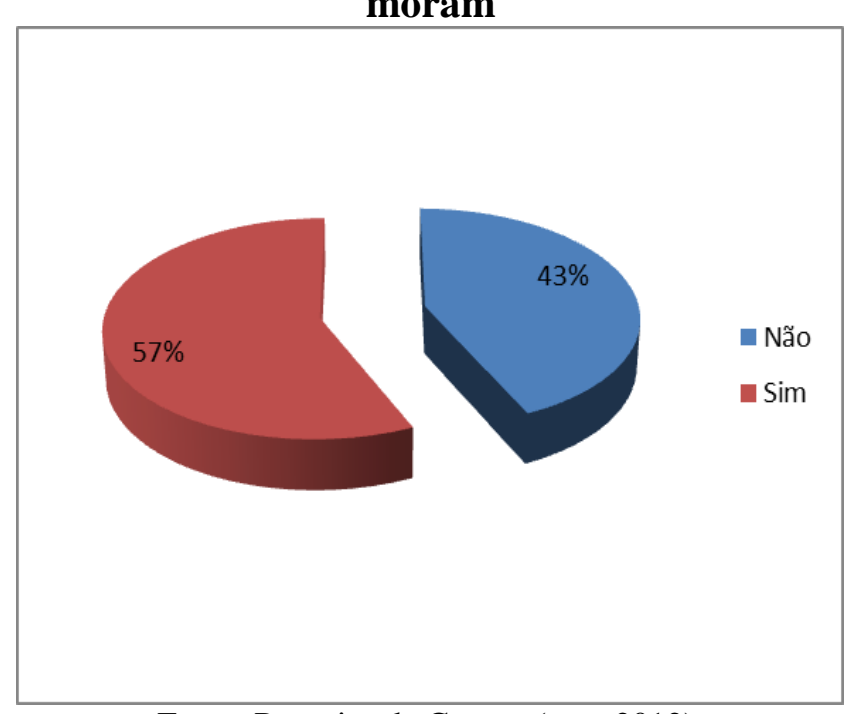

Fonte: Pesquisa de Campo (ago. 2012).

Dentre os espaços frequentados pelos moradores, destacam-se: praças, quadras, locais para caminhadas e academias. Entre os que não frequentam, as justificativas foram recorrentes, principalmente, pelo não conhecimento, falta de tempo, e, sobretudo, a violência presente nestes espaços: 
A violência urbana tem sido um dos principais argumentos para a existência do aparthaid social nas grandes cidades atualmente e para a diminuição do uso desses espaços pelos mais favorecidos socialmente. A violência nos espaços públicos das cidades apresenta-se sobre várias formas, destacando-se a descaracterização e destruição do patrimônio, os acidentes no transito, os roubos, os crimes, a prostituição, o tráfico de drogas, a luta entre gangues de jovens etc. (LIMA, 2006, p. 69).

Foi ainda questionado, para os sujeitos que afirmaram utilizar as áreas de lazer do bairro, a frequência com que o faziam, e, assim, obtiveram-se as respostas organizadas na Tabela 2.

Tabela 2 - Frequência dos moradores nos espaços públicos de lazer do seu bairro

\begin{tabular}{lcccc}
\hline \hline ZONA/BAIRRO & FREQUENTEMENTE & RARAMENTE & NÃ RESPONDEU & TOTAL \\
\hline Centro/ Mafuá & 28 & 14 & 33 & 75 \\
& $37 \%$ & $19 \%$ & $44 \%$ & $100 \%$ \\
Centro/ Piçarra & 10 & 60 & 05 & 75 \\
& $13 \%$ & $80 \%$ & $7 \%$ & $10 \%$ \\
\hline Leste/ São João & 11 & 45 & 20 & 75 \\
& $15 \%$ & $60 \%$ & $25 \%$ & $100 \%$ \\
\hline Leste/ Vale Quem & 26 & 49 & 0 & 75 \\
Tem & $35 \%$ & $65 \%$ & 0 & $100 \%$ \\
Norte/ & 26 & 40 & 09 & 75 \\
Mocambinho & $35 \%$ & $53 \%$ & $12 \%$ & $100 \%$ \\
Norte/ São & 29 & 23 & 23 & 75 \\
Joaquim & $40 \%$ & $30 \%$ & $30 \%$ & $100 \%$ \\
Sudeste/ Itararé & 35 & 40 & 0 & 75 \\
& $47 \%$ & $53 \%$ & 0 & $100 \%$ \\
Sudeste/ & 25 & 41 & 09 & 75 \\
Renascença & $33 \%$ & $55 \%$ & $12 \%$ & $100 \%$ \\
Sul/ Parque Piauí & 22 & 31 & 22 & 75 \\
& $30 \%$ & $40 \%$ & $30 \%$ & $100 \%$ \\
Sul/Saci & 35 & 07 & 32 & 75 \\
& $47 \%$ & $09 \%$ & $44 \%$ & $100 \%$ \\
\hline \hline Total & $\mathbf{2 4 7}$ & $\mathbf{3 5}$ & $\mathbf{1 5 3}$ & $\mathbf{7 5}$ \\
& $\mathbf{3 2 \%}$ & $\mathbf{4 7 \%}$ & $\mathbf{2 1 \%}$ & $\mathbf{1 0 0 \%}$ \\
\hline \hline
\end{tabular}

Fonte: Pesquisa de Campo (ago. 2012).

Apesar de a maioria dos moradores utilizarem as áreas de lazer, esta prática não faz parte de uma rotina, visto que, dentre os que frequentam $47 \%$ o fazem raramente. O que se observa é que não basta a existência dos equipamentos, têm que ser realizadas atividades de animação que possam contribuir para a utilização destes espaços. Os sujeitos da pesquisa foram questionados sobre a existência de atividades rotineiras nestes espaços, e a metade afirmou que existem, enquanto os outros afirmaram que não existe ou que não conhecem (Gráfico 02). 


\section{Gráfico 02: Existência de atividades rotineiras nos espaços públicos de lazer do seu bairro, segundo moradores pesquisados.}

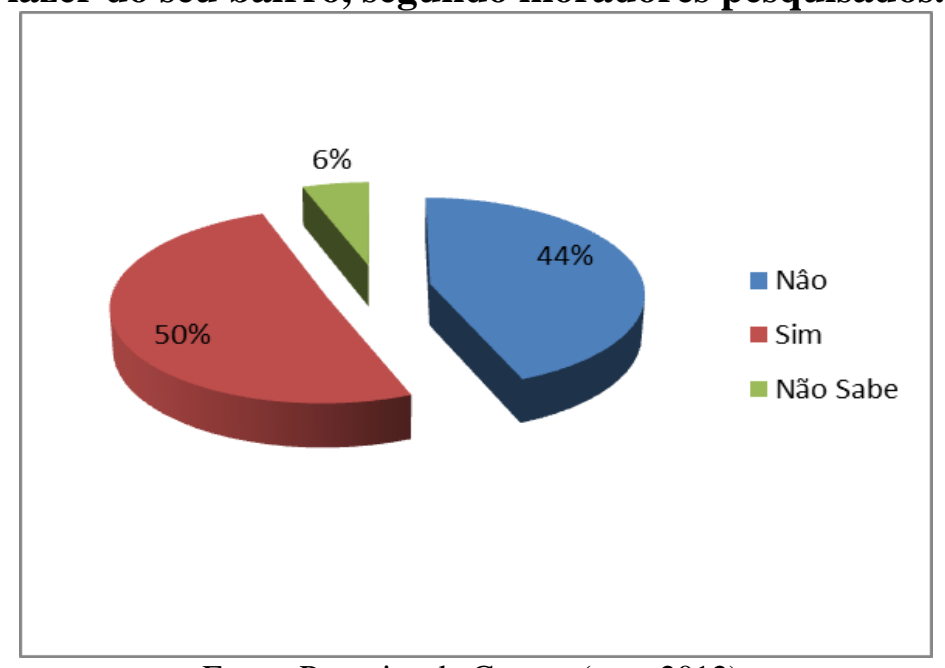

Fonte: Pesquisa de Campo (ago. 2012).

Sobre as atividades que são realizadas nos espaços públicos de lazer, foi questionado ao secretário de lazer que tipos que são realizadas para a animação destes e, como resposta, ele afirmou que são realizados campeonatos esportivos, o que demonstra que é priorizado principalmente o esporte, e, sobretudo, o futebol, favorecendo o público adulto e masculino. Não há, portanto, programações variadas que busquem atender crianças, mulheres, idosos e portadores de necessidades especiais. Outra questão investigada foi se estes moradores buscavam espaços públicos de lazer em outros bairros da cidade, pois, como já foi visto muitos bairros não possuem estes espaços.

A maioria dos sujeitos pesquisados não frequenta os espaços de lazer em outros bairros, como pode ser visualizado no Gráfico 03, o que pode acontecer devido ao deslocamento, pois muitos dependem do transporte público e, como se sabe, nos finais de semana e feriados, períodos em que as pessoas têm mais tempo disponível para o lazer, as linhas de ônibus (principal transporte coletivo de Teresina) têm o seu número reduzido, e o tempo de espera por um coletivo é muito grande, o valor das passagens, o que pode desestimular as pessoas em frequentar lugares distantes de suas residências. Outro fator que pode dificultar este acesso é a própria falta de conhecimento sobre estes espaços. 


\section{Gráfico 03: Frequência dos moradores pesquisados em espaços públicos de lazer em outros bairros da cidade}

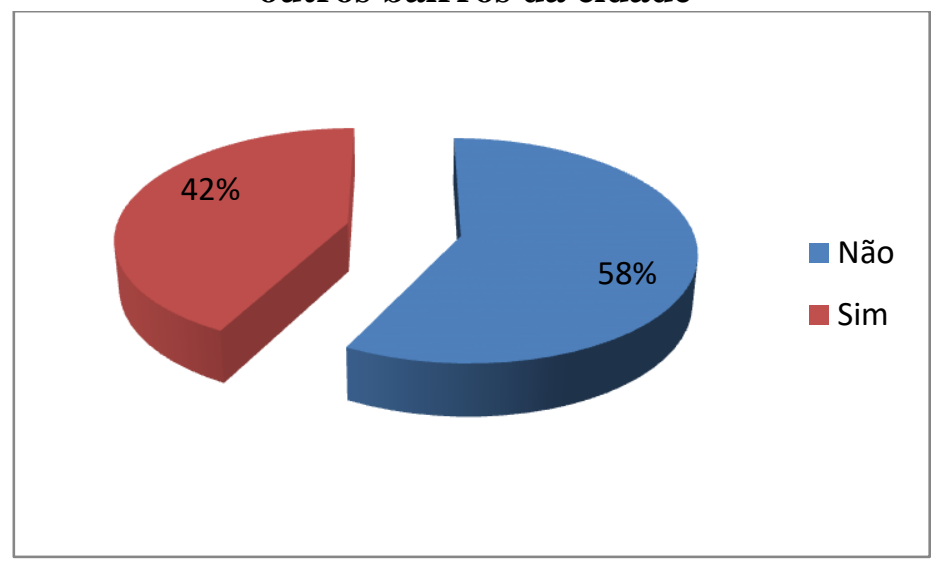

Fonte: Pesquisa de Campo (ago. 2012).

Mesmo com estas dificuldades, o percentual de pessoas que afirmam frequentar espaços de lazer de outros bairros ainda é expressivo (42\%). Dentre os locais elencados por elas, destacam-se as respostas que foram recorrentes em todas as zonas: Lagoas do Norte, Zoobotânico, pistas de caminhada e quadras de esporte.

No tocante a conservação e com base nas observações feitas em campo nos bairros pesquisados verifica-se muitos equipamentos de lazer em mau estado de conservação (Foto 2). Com aparelhos quebrados, enferrujados, sujos, com muito mato ou lixo. A maioria destes espaços é aberta ao público; dessa forma, está sujeito à ação de vândalos, dispostos a danificar o patrimônio público. Atualmente verifica-se uma falta de sensação de pertencimento por parte da população do que é público e isso facilita a ação de pessoas mal intencionadas que querem destruí-los:

Trata-se, efetivamente, do abandono, pela sociedade contemporânea, de valores essenciais que distinguiam e asseguravam o espaço público. Estamos vivenciando um momento no qual se faz presente o reducionismo do espaço público (MORAES et al., 2008, p. 105).

Soma-se a isso a desvalorização do que é público no Brasil, visto geralmente como "terra de ninguém" e caracterizado por uma má qualidade, o que causa seu abandono pelas camadas com maior poder aquisitivo, e não desperta muito o interesse das pessoas em contribuir para sua melhor conservação:

\footnotetext{
Hoje, no Brasil, a ideia de coisa pública se confunde, em grande medida, com algo de baixa qualidade ou de uso exclusivo das camadas populares, como no caso de hospitais, escolas, parques, centros de lazer, etc. de certa forma, a mesma desvalorização ocorre com o espaço público, uma vez que o acesso é livre, e a frequência majoritária é composta, em geral, de elementos oriundos dessas camadas populares (GOMES, 2006, p. 185).
} 
Por outro lado, verifica-se que a política de reparação desses equipamentos é mais lenta que a depredação, por isso, a participação da comunidade é fundamental para conservar estes espaços. A figura 03 retrata as condições do vestiário do centro esportivo do Mocambinho que está abandonado, com equipamentos quebrados e muito lixo, o que reflete o abandono deste espaço que poderia servir de suporte para os praticantes de esporte do referido centro.

\section{Figura 03: Vestiário do Centro Esportivo do Mocambinho - zona Norte}

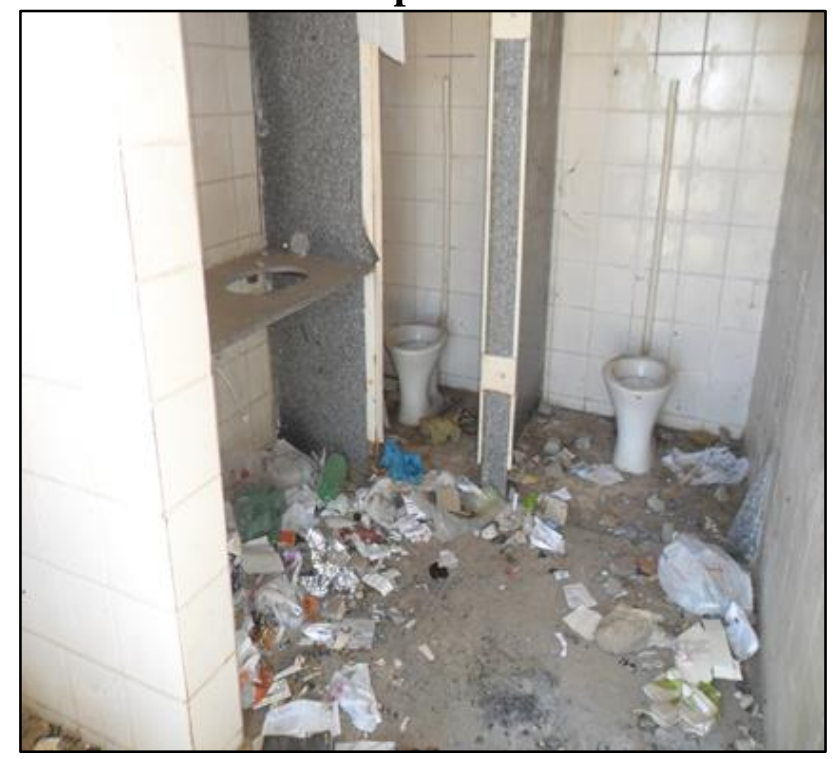

Fonte: Laudenides Pontes (2012).

Sobre a conservação dos espaços de lazer nos bairros pesquisados, 63\% dos moradores desses bairros afirmaram que não são conservados. Nos bairros Vale Quem Tem, Itararé e Mocambinho, foram registrados os maiores percentuais no que diz respeito à falta de conservação destes espaços, conforme evidenciado na tabela 03.

Tabela 03 - Conservação dos espaços públicos de lazer do bairro

\begin{tabular}{|cccc}
\hline \hline ZONA/ BAIRRO & NÃO & SIM & TOTAL \\
\hline \hline Centro/ Mafuá & 19 & 56 & 75 \\
& $25 \%$ & $75 \%$ & $100 \%$ \\
Centro/ Piçarra & 54 & 21 & 75 \\
& $72 \%$ & $28 \%$ & $100 \%$ \\
Leste/ São João & 51 & 24 & 75 \\
& $68 \%$ & $32 \%$ & $100 \%$ \\
Leste/ Vale Que Tem & 59 & 16 & 75 \\
& $79 \%$ & $21 \%$ & $100 \%$ \\
Norte/ Mocambinho & 52 & 23 & 75 \\
& $70 \%$ & $30 \%$ & $100 \%$ \\
Norte/ São Joaquim & 33 & 42 & 75 \\
& $44 \%$ & $56 \%$ & $100 \%$ \\
\hline
\end{tabular}

Sociedade e Território - Natal. Vol. 29, N. 2, p. 154-174, Jul./Dez. de 2017. 
Continuação da tabela 03

\begin{tabular}{cccc}
\hline \hline ZONA/ BAIRRO & NÃO & SIM & TOTAL \\
\hline \hline Sudeste/ Itararé & 54 & 21 & 75 \\
& $72 \%$ & $28 \%$ & $100 \%$ \\
Sudeste/Renascença & 50 & 25 & 75 \\
& $67 \%$ & $33 \%$ & $100 \%$ \\
Sul/ Parque Piauí & 48 & 27 & 75 \\
& $64 \%$ & $36 \%$ & $100 \%$ \\
Sul/Saci & 48 & 27 & 75 \\
& $64 \%$ & $36 \%$ & $100 \%$ \\
\hline \hline Total & $\mathbf{4 6 8}$ & $\mathbf{2 8 2}$ & $\mathbf{7 5 0}$ \\
& $\mathbf{6 3 \%}$ & $\mathbf{3 7 \%}$ & $\mathbf{1 0 0 \%}$ \\
\hline \hline
\end{tabular}

Fonte: Pesquisa de Campo (ago. 2012).

No tocante à participação da população do bairro em conservar os espaços públicos de lazer, a maioria dos entrevistados (59\%) reconhece que os próprios moradores do bairro não cumprem seu papel em ajudar na conservação.

\section{Gráfico 04: Participação dos moradores pesquisados na conservação dos espaços públicos de lazer do seu bairro}

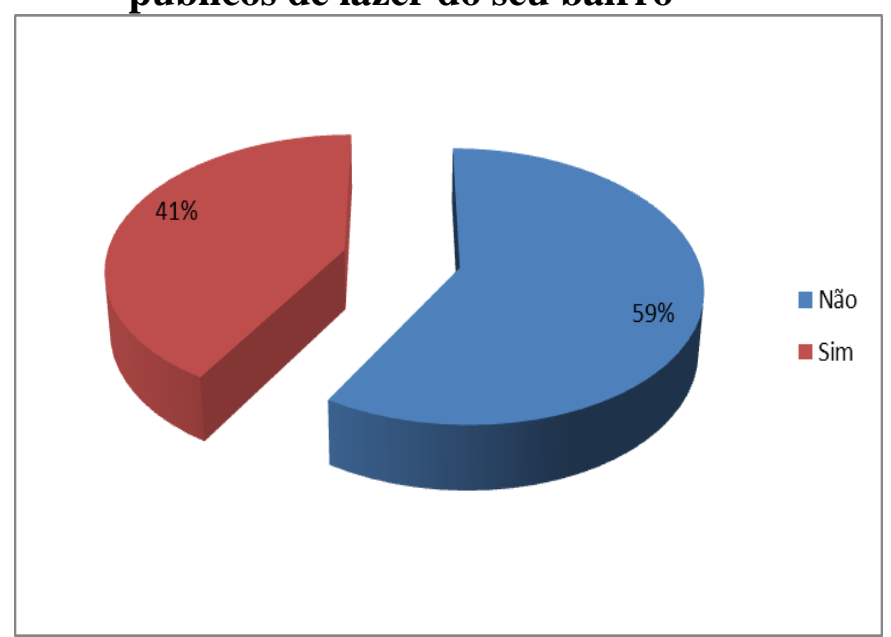

Fonte: Pesquisa de Campo (ago. 2012).

Um exemplo do descaso de algumas pessoas com os espaços públicos foi noticiado por matéria jornalística (Figura 04).

Nesse contexto, surge outra inquietação: - De quem seria a responsabilidade pela conservação destes equipamentos? Que políticas seriam necessárias para manter estes equipamentos em um estado desejável para o uso? Ao mesmo tempo reflete-se que o cuidado com o patrimônio público deveria ser de todos os órgãos competentes em estar atentos, tanto para a manutenção quanto para a físcalização e punição de vândalos e também da própria 
sociedade que deve estar vigilante e zelosa para cuidar do patrimônio que é custeado por todos. É necessário, portanto, um trabalho coletivo para a conservação dos espaços de lazer:

Figura 04: Moradores do Promorar lançam resíduos em praça pública

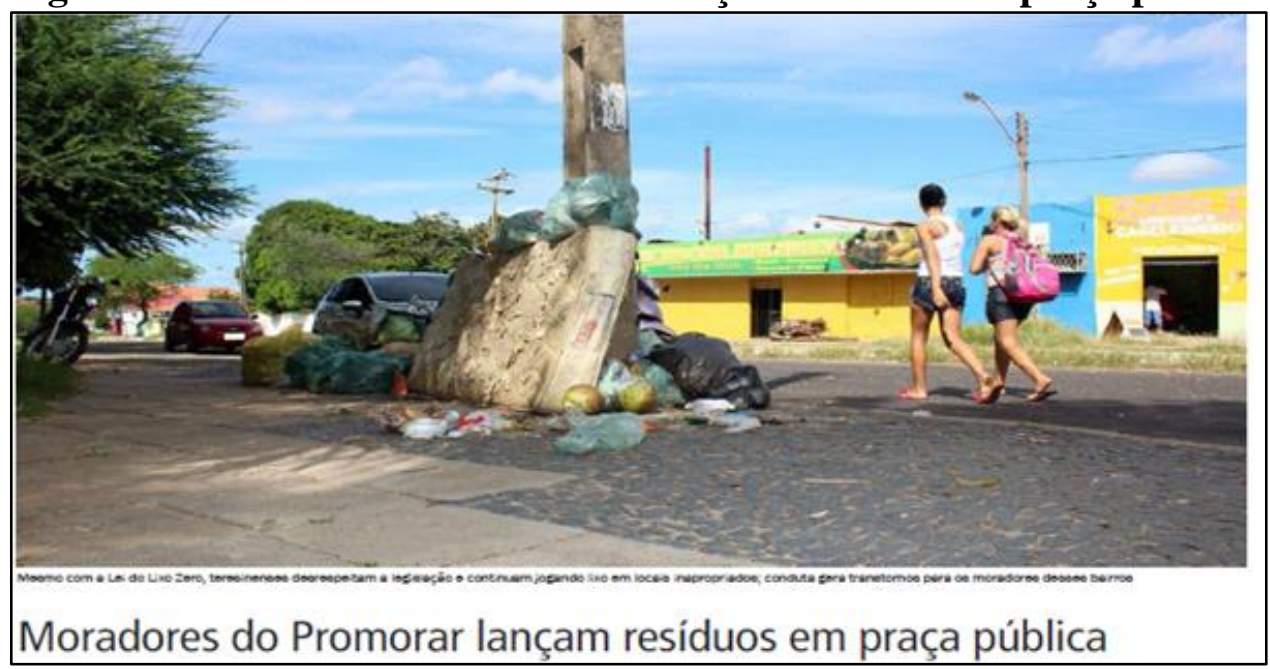

Fonte: Jornal O Dia, 14 maio 2014, p. 4.

Uma política de lazer adequada pode incentivar a integração do cidadão aos seus grupos de referencia mais próximos, como os vizinhos de rua ou bairro, frequentando associações de cunho cultural e esportivo. Nos dias de hoje quando nenhum governo parece capaz, ou disposto, a arcar sozinho com as suas responsabilidades sociais esta rede de solidariedade e amizade pode ser utilizadas em programas de mutirão e auxilio mútuo, nos quais a população com o apoio do poder publico procura resolver seus problemas mais imediatos (GUTIRREZ, 2001, p. 115).

Algumas iniciativas já foram tomadas pelo poder público, no sentido de incentivar uma maior preocupação e cuidado da população para com os espaços de lazer, como foi noticiado na mídia (Figura 05).

Figura 05: Campanha incentiva preservação de quadras

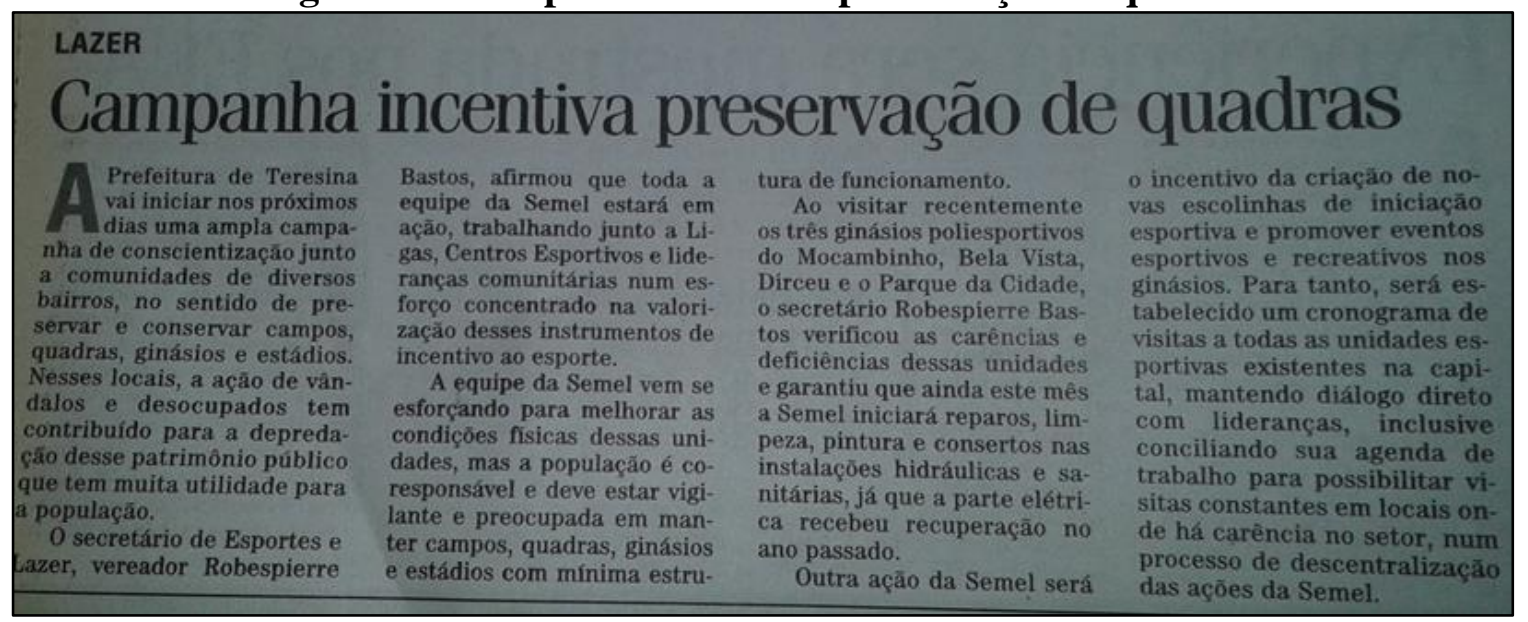

Fonte: Jornal O Dia, 11 mar. 2003.

Sociedade e Território - Natal. Vol. 29, N. 2, p. 154-174, Jul./Dez. de 2017. 
Indagado sobre como acontece à manutenção dos espaços de lazer, o secretário de lazer respondeu:

A política adotada pela gestão atual é de conservar os equipamentos existentes antes, primeiro e, só depois, construir novos. A comunidade nem sempre colabora com a manutenção, que é muito cara, principalmente nos campos que necessitam de nivelamento e reposição dos alambrados periodicamente. As academias populares também precisam de manutenção para conserto periódico dos aparelhos.

A problemática do lazer nas cidades vai além da oferta de espaços, pois é preciso que haja políticas de animação; ou seja, atividades que envolvam a população e façam esta sentirse pertencente a este espaço, o que se torna muito difícil no atual mundo globalizado. Sem este sentimento de pertencimento, muitos enxergam estes espaços como algo estranho, distante de sua realidade, e por isso não contribuem para sua conservação: jogando lixo, quebrando, e, ainda, não fiscalizando. Os moradores foram ainda questionados sobre seus anseios, a respeito do que poderia ser feito no seu bairro para uma melhoria no lazer. As respostas estão dispostas no Gráfico 05, a seguir:

\section{Gráfico 5 - O que poderia ser feito para melhorar o lazer do bairro, segundo os moradores pesquisados}

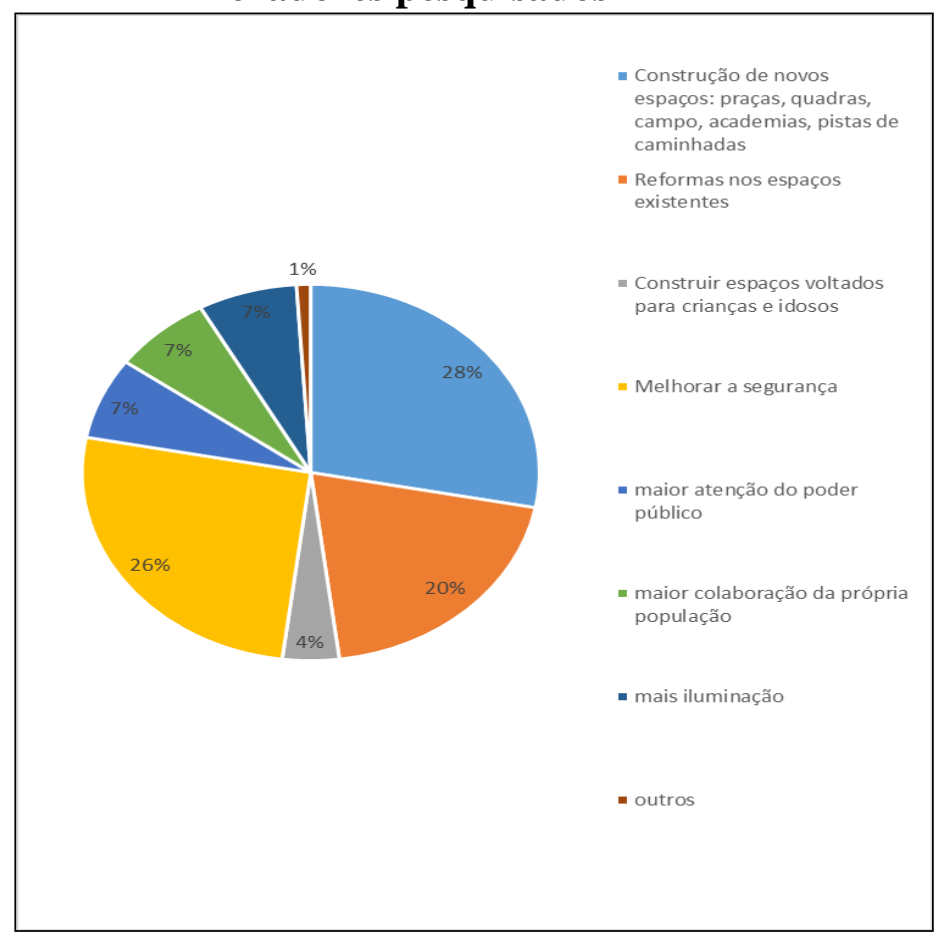

Fonte: Pesquisa de Campo (ago. 2012).

Verificou-se que a maioria vê a necessidade da construção de novos espaços, pois, em muitos bairros de Teresina-PI, estes espaços estão em número pequeno, ou ainda, há aqueles que não possuem nenhum tipo de equipamento, o que reafirma as considerações de que os Sociedade e Território - Natal. Vol. 29, N. 2, p. 154-174, Jul./Dez. de 2017. 
espaços que existem não atendem plenamente às necessidades atuais da população, pois não acompanham seu crescimento, e as localizações não são coerentes com as demandas. Além disso, a população solicita a reforma dos espaços já existentes. Como já foi dito, muitos destes encontram-se abandonados e sem condições de uso.

A segunda maior preocupação dos moradores para a melhoria do lazer é a segurança, uma vez que os espaços públicos na cidade contemporânea são em sua maioria considerados inseguros. Outra solicitação é a construção de espaços para idosos e crianças, parcelas da população que encontram poucas opções no espaço público. Ao analisar a relação dos moradores com os espaços públicos de lazer na cidade de Teresina-PI, constatamos que alguns fatores impedem maior utilização, sobretudo a violência que torna estes espaços inseguros. Além disso, a falta de atividades ou até mesmo a falta de conhecimento sobre estas atividades, problemas com iluminação, limpeza e manutenção dos equipamentos esportivos também são barreiras.

A segurança foi outro fator, pois, conforme discutido, os problemas urbanos não podem ser tratados de maneira isolada, pois acaba refletindo o no outro. A violência recorrente hoje nas cidades afasta as pessoas do espaço público, visto que este, muitas vezes, é também lugar dos excluídos e de atividades ilícitas, ponto de prostituição, lugar de repouso de andarilhos ou mendigos; tráfico e consumo de drogas (Figura 06).

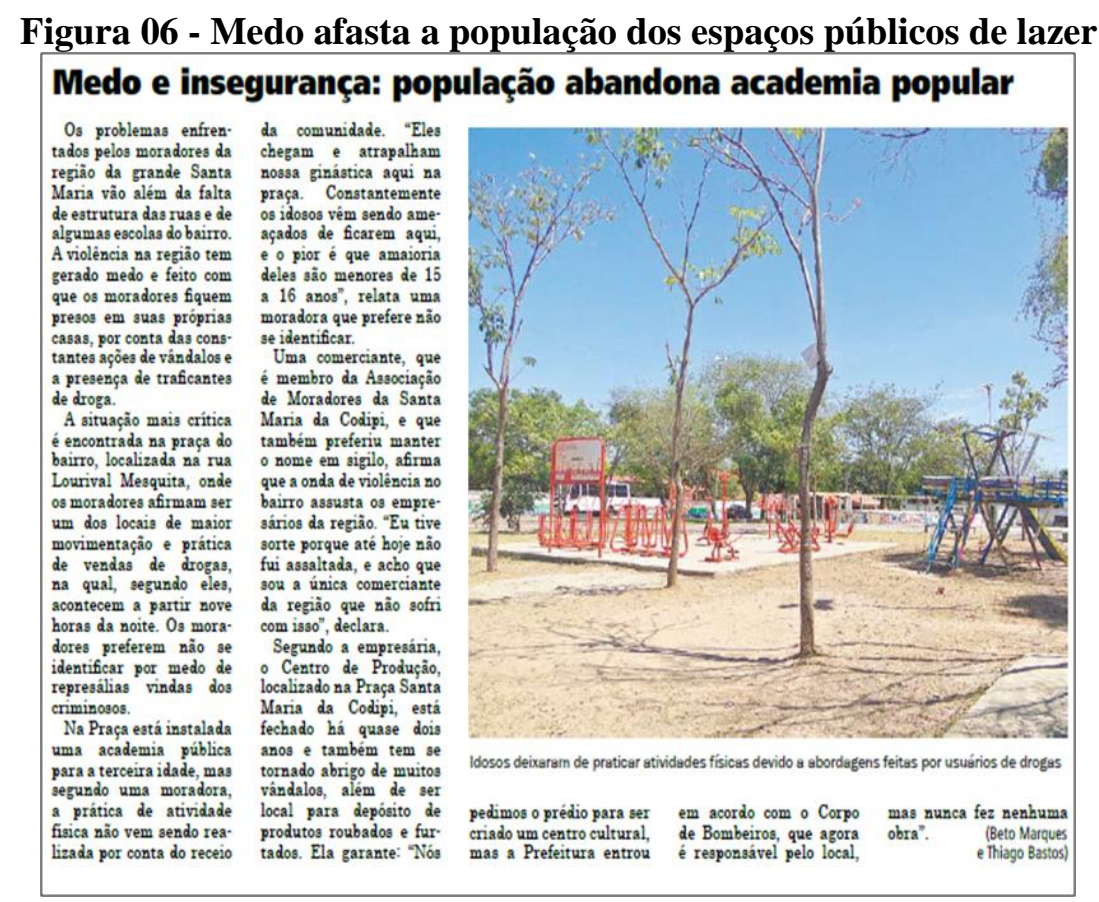

Fonte: Jornal O Dia, 14 set. 2013, Caderno em Dia, p. 1. 
Como afirma Marcellino (2006) os problemas sociais não estão isolados, mas sim interligados, não podem ser colocados em escala de prioridades: "Não é possível se entender o lazer isoladamente, sem relação com outras esferas da vida social. Ele influencia e é influenciado por outras áreas, em uma relação dinâmica. Não entender esse processo pode levar a equívocos que são muito comuns" (MARCELLINO, 2006, p. 14).

Outros fatores citados foram: maior atenção do poder público, maior colaboração da própria população, reforma de áreas já existentes, mais lazer para crianças e idosos - muitas vezes excluídos, pois os espaços privilegiam alguns grupos: "Além disso, no plano cultural, uma série de preconceitos restringe a prática do lazer aos mais habilitados, aos mais jovens e aos que se enquadram nos padrões estabelecidos de "normalidade"” (MARCELLINO, 2008, p. 14).

\section{CONSIDERAÇÕS FINAIS}

O lazer contribui de forma significativa para a apropriação dos espaços públicos da cidade, e, consequentemente, para uma vivência mais significativa da cidade, pois o indivíduo amplia sua escala para além de sua própria casa, interagindo com o bairro e cidade. Algumas dinâmicas visíveis no espaço público revelam muito sobre a sociedade, como, por exemplo, o crescimento da violência, a mercantilização, o seu abandono e desvalorização pelos próprios usuários.

Sobre a utilização dos espaços públicos de lazer constatou-se que ainda há muitas pessoas que utilizam estes espaços, no entanto, é notório que a vivência de um lazer nos espaços públicos das cidades na sociedade atual esbarra em vários entraves; A falta de conservação dos espaços tanto pela ineficiência das politicas públicas como também pela ação do vandalismo e omissão da comunidade; a falta de programação nesses espaços e ainda a violência urbana dificulta a utilização destes espaços.

É evidente que as soluções para estes entraves não são medidas específicas, mas permeiam vários setores, assim como foi citado pela própria população, as medidas vão desde ações específicas como a construção, manutenção e animação dos espaços para todos os públicos até mudanças com relação a conduta da própria sociedade no sentido de colaborar com a manutenção desses espaços e a diminuição da violência urbana. 


\section{REFERÊNCIAS}

AZEVEDO, Ricardo José Gontijo. O espaço público nas cidades médias: análise da dinâmica socioespacial de praças e parques em Limeira-SP. Tese (Doutorado) - Universidade Estadual Paulista, Rio Claro, 2013.

CUNHA, Rita Dione Araújo. Os espaços públicos abertos e as leis de uso e ocupação: uma questão de qualidade para ambientes sustentáveis. Anais... apresentado no III Encontro Nacional Sobre Edificações e Comunidades Sustentáveis (ENECS), 2003.

DUMAZEDIER, Joffre. Sociologia empírica do lazer. Tradução de Sílvia Mazza e J. Guinsburg. São Paulo: Perspectiva, 2008.

GIL, Antônio Carlos. Como elaborar projetos de pesquisa. 5. ed. São Paulo: Atlas, 2010.

GOMES, Paulo Cesar da Costa. A condição urbana: ensaios de geopolítica da cidade. 2. ed. Rio de Janeiro: Bertrand Brasil, 2006.

GOMES, Christianne Luce; MELO, Victor Andrade de. Lazer no Brasil: trajetória de estudos, possibilidades de pesquisa. Movimento Porto Alegre, v. 9, n. 1, p. 23-44, jan./abr. 2003.

GUTIERREZ, G. L. Lazer e prazer: questões metodológicas e alternativas políticas. Campinas: Autores Associados, 2001.

LIMA, Dália Maria Maia Cavalcanti de. O espaço de todos, cada um no seu lugar: o uso dos espaços públicos destinados ao lazer em Natal. 2006. 250p. Tese (Doutorado em ciências sociais) - Programa de Pós-Graduação em Ciências Sociais, Universidade Federal do Rio Grande do Norte, Natal, 2006.

MARCELLINO, Nelson Carvalho. Lazer e humanização. Campinas-SP: Papirus, 2001.

Estudos do lazer: uma introdução. 3. ed. Campinas: Autores Associados, 2006.

MARCELLINO, Nelson Carvalho (Org.). Lazer e sociedade: múltiplas relações. 3. ed. Campinas: Alínea, 2008.

MARCELLINO, Nelson Carvalho, BARBOSA, Felipe soligo, MARIANO, Stephanie Helena. Espaços e equipamentos de lazer: apontamentos para uma política pública. In: MARCELLINO, Nelson Carvalho (Org.). Políticas públicas de lazer. Campinas-SP: Alínea, 2008.

MORAES, A. A. G. de; BERETA, A. S.; CALIXTO, M. J. M. S.. Entre o público e o privado: uma discussão sobre a apropriação das calçadas. In. CALIXTO, M. J. M. S. O espaço urbano em redefinição. Dourados, MS: UFGD, 2008.

TERESINA. Secretaria Municipal de Planejamento-SEMPLAM. Teresina em Bairros 2013. Teresina: Prefeitura Municipal de Teresina, 2013. Disponível em: <http://semplan.teresina.pi.gov.br/teresina-em-bairros>. Acesso em 17/07/2013

\section{Recebido em Julho de 2017}

Aprovado em Novembro de 2017

Publicado em Dezembro de 2017

Sociedade e Território - Natal. Vol. 29, N. 2, p. 154-174, Jul./Dez. de 2017. 